\title{
Prediction of the Performance of Elite Male Trampolines Based on Body Composition Indices
}

\author{
Sertaç Erciş \\ Correspondence: Sertaç Erciş, Faculty of Sport Sciences, Ataturk University, Erzurum, Turkey.
}

Received: January 24, 2018

doi:10.11114/jets.v6i4a.3152
Accepted: March $312018 \quad$ Online Published: April 1, 2018

URL: https://doi.org/10.11114/jets.v6i4a.3152

\begin{abstract}
Main purpose of this study was Prediction of the performance of elite male trampolines based on body composition indices. To this aim, 45 male athletes (age 14.17 $\pm 2.86 \mathrm{yrs}$, athletic experience 7.22 \pm 3.64 yrs and competitive experience $3.31 \pm 2.44 \mathrm{yrs}$ ), who participated in the national trampoline team's preparation camps for participation at the 2014 Asian Games in four age categories included Children (ages 11 and 12 yrs), Juniors (ages 13 and 14 yrs), Adolescents (ages 15 to $17 \mathrm{yrs}$ ) and Seniors (ages 18 yrs $<$ ) were selected using targeted sampling. Variables of study included 24 body composition indices which were measured using standard procedures and instruments. Data were analyzed using Pearson correlation coefficient and multiple regression models at the 0.05 significance level. Results of study showed that, among all relationships between variables, only the relationships of the shoulder belt muscle strength $(r=0.294)$ with performance are statistically significant and in other cases, observed relationships were not statistically significant $(p>0.05)$. Findings of this study suggest that, in the high competitive level of trampoline body composition indices have not predictive role in preparation programs of elite male trampolines.
\end{abstract}

Keywords: body composition, trampoline, elite athlete

\section{Introduction}

Trampoline's competition has become one of the most important sports events in Asia and the Olympics, and has attracted the attention of champions in recent years. National teams of this field are regular and with long-term planning in the country and their national teams are represented in various international competitions. In the meantime, competitive success in this sport requires the development of physical and mental training programs for athletes, which, in turn, requires detailed information on the requirements of the field of trampoline and the importance of each. The factors involved in athletic performance should be studied scientifically and systematically. Unfortunately, despite the importance of the field of trampoline, very little attention has been paid by domestic and foreign researchers to this sport, and there is no accurate information about it. The results of extensive research in the field of championship sport show that the ideal sport performance in any sport is influenced by a combination of morphological, physiological, psychological and socio-cultural factors (MacMillan 2007). Although it is worth exploring how to combine these factors into each and every field of sport separately and proprietary, however, due to the lack of research in the field of trampoline, and on the other hand, the close connection between the trampolines and gymnastics, scientific information reported in gymnastics. Studies conducted on gymnasts show that these athletes have special morphological, physiological and psychological needs.

For example Douda et al. (2008) in their research on elite and amateur groups of gymnasts showed that $45 \%$ anthropometric components are involved in gymnastic performance. In a more comprehensive research, Nozuhuri (2016) showed that the role of anthropometric features in the performance of elite gymnasts is $24.2 \%$. Despite the knowledge provided in the field of gymnastics, it seems that the requirements of the trampoline range are different in some sports-related factors than gymnastics. For example, trampolines may have a higher need for static and dynamic equilibrium than their gymnasts. Also, in a coordinated two-dimensional competition, athletes in this field will need more time to take photos and coordinate their movements. In a recent study by Gomez-Landro et al. (2010) studied the species and body composition of the tropical women of the elite female elderly. The results of this study showed that trampolines have different types of physical shape, such that trampolines have less ectomorph in their physical form and are more indomorphic. This evidence can be a reason for different requirements of Trampolines and gymnastics discipline. However, due to the lack of research in the field of trampoline, the information available on analyzing the needs of this field is in the speculations of experts, and definitive comments on it cannot be presented. Accordingly, the 
present research aims to determine and prioritize the needs of the trampoline field, which seeks to investigate the correlation of selected physical capabilities with the performance of elite male trampolines at different age ranges, including preterm infants, adolescents, young adults and adults and to predict the performance of these athletes on the basis of physical fitness.

Dzhafarov \& Vasil'chuk (1987) examined the anthropometric characteristics of elite female gymnasts that gymnasts with a technical level of leveling (scores of about 10) had similar anthropometric profiles. Faria and Faria (1989) concluded that the association between anthropometric and physical characteristics of elite young men's gymnasts with competitive performance led to the conclusion that class 1 gymnasts were with a shorter stature, relative strength and absolute, higher muscle mass.

Lindner, Caine \& Johns (1991) in the study of physical and functional predictors by withdrawal competitive female gymnasts concluded that withdrawal gymnasts were older, taller and heavier, which were the reason for their higher strength, power, speed, and endurance. Discontinued gymnasts with less skinny physics/ ectomorphic with less muscle had better recordings in most of the flexibility tests.

Casenz et al. (1991) concluded that anthropometric characteristics of elite female and male gymnasts were found to be associated with competitive aging sport with a special composition and structure (less fat and lower indomorph). Sherman et al. (1996) studied the relationship between BMI and athletic performance in female elite gymnastics that after age control as a factor affecting body mass index, rank and body mass index, A curve-shaped relationship exists, such that a low-body mass index is associated with a higher class and a very low-body mass index is associated with low-level one. Claessens \& Lefevre (1998) in examining the morphological and functional characteristics as the foreclosure predictors in female gymnasts in Belgium concluded that anthropometric variables and physical fitness are not an important factor in quitting the championship competitions and only age is a decisive factor that may be related to social and psychological factors.

Ghazizadeh (1999) evaluated the measurement of upper extremity strength and limb strength of female gymnasts in the country with non-athlete girls 12 to 17 years old. There was no significant difference between height, weight, anthropometric measures and upper extremity strength in two groups of gymnasts and non-athletes.

Casenz et al. (1999) examined the role of anthropometric features in the performance of elite female gymnasts and concluded that there was a moderate and inverse association between the score of gymnasts in the balance body and the thickness of the skin of the dorsal joint in China, while there was a strong and inverse association between the overall performance of the gymnasts and the indomorphic component. These results suggest that gymnasts with lower subcutaneous fat and higher endomorphisms have lower performance.

Ackland et al. (2000) examined the effect of body size growth on the four-month period on rotational performance in gymnasiums. Short gymnasts with higher strengths have more potential to implement skills that involve the whole body. Taller gymnasts, while capable of generating more power and angular velocities, are not as good as short-range gymnasts.

Grantham (2000) studied the physiological and anthropometric characteristics of male and female gymnasts at national and international competitive levels. Men and women gymnasts at international competitive levels have significantly lower fat percentages than national gymnasts at their national level.

Grandjean, Taylor \& Weiner (2002) in examining the relationship of assurance in implementing and focusing on competitive performance in gymnasiums at the 2000 Olympics, it was found that reliance on gymnastics implementation did not directly correlate with performance, but the linkage with the mediation of gymnastic focus was on the run.

Giorpopoulos et al. (2004) concluded men's gymnasts with body less fat began to practice better compared to those with a taller height, lower lumbar bone age and higher body mass index. Rodriguez and Bral Di La Rosa (2006) in their study described the anthropometric profiles of male elite male gymnasts and concluded that the structure of the elite Argentine gymnasts has a biomechanical advantage in comparison with outstanding gymnasts Is not higher and may interfere with their competitive performance.

Douda et al. (2008) in identifying physiological and anthropometric predictors of rhythmic gymnastics, it was concluded that anthropometric, aerobic, flexural and explosive power characteristics were reported as important determinants of successful performance.

Di Cagno et al (2008) considered the anthropometric characteristics of young and adult elite gymnasiums in Italian rhythmic gymnastics between 2002 and 2006. The effect of the time period is only significant on the width of the two shoulders and the pelvis. There was no significant difference between the 2002 and 2006 gymnasts' characteristics. These results indicate that the growth pattern of male gymnasts is the same as ordinary people, with the difference that 
male gymnasts are mostly selected from the beginning with unique features.

In a study aimed at identifying factors affecting motor performance in amateur gymnastics with an emphasis on gender differences, the results showed that height, length of the lower limbs and body fat were positively and moderately correlated with the mean of 0.4 to 0.6 with jump height and flight time in gymnastics skill tests, which indicates the importance of these factors in the gymnastics motor performance.

Gómez-Landero et al. (2010) in the study of the species and physical composition of the Spanish elite female gymnasts in trampoline concluded that trompolins have different physical types of other gymnasts, such that the trampolines have a lower electroformity and indomorphic.

Zuniga et al. (2011) examined the annual changes in anthropometric characteristics of high school female gymnasts in comparison with national norms and concluded that participation in gymnastics did not have a negative effect on the physical growth pattern. Vandorpe et al. (2011) considered the factors that differentiate the various competitive levels of gymnasts from the conclusion that motor coordination is the most important factor in the elimination of elite gymnasiums.

Dashti (2016) studied the relationship between anthropometric characteristics and physical fitness factors with the performance of the superior male gymnasts in Iran. The variables such as height, height, length of two hands, fat weight, body weight without fat, strength of fingers and the power has a significant relationship with the performance of neonatal gymnasts. However, there was no significant relationship between the width of shoulder, hip width, hip length, percentage of fat and pelvic flexibility.

\section{Materials and Methods}

The present research is considered as a practical one and in terms of the method is a predictive correlation research.

\subsection{Society, Sample and Sampling Method}

The statistical population of the study was all male trampolines who were invited to gymnastics training camps in 2014 to participate in Asian Games 2014 and participated in competing selections within the campus. These include 48 athletes in six competitive age groups including L5, L6, L7, L8, youth and adults and low, which included 11, 12, 13, 14, 15-17 and 18 years old or more respectively.

In a more general division, 48 athletes were invited to the national team camps in four age groups (11 and 12 years old), adolescents (13 and 14 years of age), youth (15-17 years) and adults (18 years) (In each age group 12 people). Due to the limited number of people in the statistical population, non-random sampling method was used. As a result, the research sample was equal to the statistical society. However, 3 people in camps were unable to complete measurements due to injury, which dropped out of the sample and the number of samples dropped to 45. All participants, with full knowledge of the goals and implementation process, participated in this study with full satisfaction.

\subsection{Measuring Tools and Equipment}

In the present study, the following tools and equipment were used to measure the variables of the research:

1. Researcher-made questionnaire for collecting individual information of subjects

2. Digital scales with accuracy of $0.01 \mathrm{~kg}$ equipped with a precision 0.005 meter with SOEHNLE® marking Made in Germany to measure the height and weight of subjects

3. Anthropometric meter with Quick Medical ${ }^{\circledR}$ marker ANTTAPS US for measuring distance and lengths in different tests

4. Body composition analysis device with Zeus $+9.9+$ Swiss model for determining the body composition of subjects

5. Standard trunk flexural test for measuring the flexural strength of the front trunk

6. Refereeing Board and Rules of Arbitration of Federation to measure the performance of the subjects.

\section{Measurements}

3.1 Personal Information

Participants' individual information was comprised of eight questionnaires for determining age, competitive age, sporting history, competitive history, membership in the national team, weekly physical and psychological hours, and collecting history records, respectively, using a researcher-made questionnaire. 


\subsection{Body Composition}

Body composition analysis was used to analyze body composition using the Mark $9.5+9.9$ model. Indicators used in this study included height, body mass, body mass index, intercostal water content, protein percentage, soluble mineral content, fat percentage and fat mass and muscle of the body. In calculating various indices were used.

\subsection{Competitive Performance in the Implementation of Trampolines}

In order to measure the level of performance of the participants, information about the selection of the camp that was carried out according to the laws of gymnastics federation was used. Based on this intra-camp competition, each participant will execute 20 trampoline motor skills and assess the quality of the performance by five national referees. The range of scores provided by each referee is between 0 and 20, which is based on the qualitative analysis parameters of skill implementation for each participant. Accordingly, the score for each participant's score is between 0 and 400. In calculating the performance score, at first, the minimum and maximum grades are eliminated from the five points given for each skill and the average of the three remaining scores is calculated.

\subsection{Competitive Performance in the Implementation of Trampolines}

In order to measure the level of performance of the participants, information about the selection of the camp that was carried out according to the laws of federation was used. Based on this intra-camp competition, each participant will execute 20 trampolines motor skills and assess the quality of the performance by five national referees.

The range of scores provided by each referee is between 0 and 20, which is based on the qualitative analysis parameters of skill implementation for each participant. Accordingly, the score for each participant's score is between 0 and 400 . In calculating the performance score, at first, the minimum and maximum grades are eliminated from the five points given for each skill and the average of the three remaining scores is calculated.

Participants were also asked to respond to the questions with integrity and precision, given that there was no right or wrong answer in the questionnaires. At the end of the coordination session, the recommendations were provided by the researcher to the participants about the amount of sleep, nutrition and rest. Then, after coordinating with the physical fitness laboratory of University, a body composition measure was performed. At the first session, body composition was measured.

During each session, participants were asked to run a standard heating protocol that was led by the coaches of the Trampoline national team for 10 minutes. Before each test, the correct implementation of the error and error criteria and the evaluation of the implementation were explained by the laboratory experts and, if any questions were answered, the items were answered. Participants were allowed to review their implementation practices before performing the main tests. To prevent fatigue, a rest time test was considered sufficiently. Each measurement session was terminated with a standard cooling protocol. Finally, information about the level of trampoline performance at the end of the training camp was received from the technical team members.

\subsection{Data Analysis Method}

In the data analysis, firstly, the natural assumption of the distribution of data was investigated using Shapiro Wilk's test. Considering the prediction of the natural distribution of the data, Pearson correlation coefficient was used. All analyzes were performed at 95\% confidence level using Excel software and SPSS version 21.

\section{Results}

Table 1. Descriptive statistics relating to the individual characteristics of the participants Characteristics of statistical indicators

\begin{tabular}{l|l|r|l}
\hline & N & M & SD \\
\hline Age (years) & 45 & 14.17 & 2.86 \\
\hline Sport record (years) & 45 & 7.22 & 3.64 \\
\hline Competition (years) & 45 & 3.31 & 2.44 \\
\hline
\end{tabular}

Individual characteristics in Table 1 show that age, sport history and competitive history of the participants in the study. 
Table 2. Distribution of participants based on selected sport variables

\begin{tabular}{|c|c|c|c|}
\hline \multirow{2}{*}{$\begin{array}{l}\text { Characteristic } \\
\text { Competitive age }\end{array}$} & \multirow{2}{*}{ Subcategory } & \multicolumn{2}{|c|}{ Statistical indices } \\
\hline & & $\mathrm{N}$ & $\%$ \\
\hline & L5 (born in 2001) & 8 & $\% 17.8$ \\
\hline & L6 (born in 2000) & 7 & $\% 15.6$ \\
\hline & L7 (born in 1999) & 8 & $\% 17.8$ \\
\hline & L8 (born in 1998) & 4 & $\% 8.9$ \\
\hline & Youth (born 1996-97) & 6 & $\% 13.3$ \\
\hline & Adults (born in 1995 and below) & 12 & $\% 26.7$ \\
\hline \multirow{2}{*}{$\begin{array}{l}\text { history of membership in the national } \\
\text { team }\end{array}$} & $\mathrm{Y}$ & 19 & $\% 42.2$ \\
\hline & $\mathrm{N}$ & 26 & $\% 57.8$ \\
\hline
\end{tabular}

Table 2 indicates the age category of competitive groups.

Table 3. Descriptive statistics related to height, body mass and body mass index by age group Competitive age variable of statistical indices

\begin{tabular}{|c|c|c|c|c|}
\hline \multirow[t]{2}{*}{ Variable } & \multirow[t]{2}{*}{ Age } & \multicolumn{3}{|l|}{ Statistic indices } \\
\hline & & $\mathrm{N}$ & $\mathrm{M}$ & SD \\
\hline \multirow[t]{6}{*}{ Height $(\mathrm{cm})$} & L5 & 8 & 135.43 & 7.26 \\
\hline & L6 & 7 & 149.57 & 6.32 \\
\hline & L7 & 8 & 155.56 & 7.30 \\
\hline & L8 & 4 & 156.87 & 7.98 \\
\hline & Youth & 6 & 163.33 & 6.50 \\
\hline & Adults & 12 & 172.01 & 5.54 \\
\hline \multirow[t]{6}{*}{ Body mass } & L5 & 8 & 31.16 & 4.69 \\
\hline & L6 & 7 & 40.12 & 5.41 \\
\hline & L7 & 8 & 43.01 & 8.95 \\
\hline & L8 & 4 & 44.77 & 8.80 \\
\hline & Youth & 6 & 52.25 & 10.79 \\
\hline & Adults & 12 & 65.16 & 4.50 \\
\hline \multirow{6}{*}{$\begin{array}{l}\text { Body mass index } \\
(\mathrm{kg} / \mathrm{m})\end{array}$} & L5 & 8 & 16.60 & 1.97 \\
\hline & L6 & 7 & 17.64 & 1.57 \\
\hline & L7 & 8 & 17.57 & 2.26 \\
\hline & L8 & 4 & 18.12 & 2.33 \\
\hline & Youth & 6 & 19.10 & 2.79 \\
\hline & Adults & 12 & 22.04 & 1.70 \\
\hline
\end{tabular}

Table 3 data shows that height, body mass, and body mass index are differentiated according to the age group of individuals.

Table 4. Descriptive statistics on the composition of muscle mass and body fat in different organs

\begin{tabular}{l|r|r|r}
\hline & $\mathrm{N}$ & $\mathrm{M}$ & $\mathrm{SD}$ \\
\hline Straight muscle mass (\%) & 45 & 18.18 & 2.32 \\
\hline Right hand (\%) & 45 & 4.72 & 0.70 \\
\hline Right foot (\%) & 45 & 13.45 & 1.81 \\
\hline Left muscular mass (\%) & 45 & 18.35 & 2.17 \\
\hline left hand (\%) & 45 & 4.41 & 0.90 \\
\hline Left foot (\%) & 45 & 13.93 & 1.64 \\
\hline Trunk muscle mass (\%) & 45 & 36.81 & 3.48 \\
\hline Right Fat Mass (\%) & 45 & 1.17 & 0.61 \\
\hline Right hand (\%) & 45 & 0.30 & 0.11 \\
\hline Right foot (\%) & 45 & 0.86 & 0.54 \\
\hline Fat mass of the left limb (\%) & 45 & 1.17 & 0.63 \\
\hline left hand (\%) & 45 & 0.31 & 0.12 \\
\hline Left foot (\%) & 45 & 0.85 & 0.53 \\
\hline Trunk fat mass (\%) & 45 & 9.51 & 0.76 \\
\hline Left and Right Left Musculoskeletal Difference (\%) & 45 & 0.46 & 0.75 \\
\hline Difference in fat mass of the right and left limbs (\%) & 45 & 0.035 & 0.08 \\
\hline
\end{tabular}

Table 4 shows that the difference between left and right leg muscles is $0.46 \pm 0.75$ percent of the body mass among elite 
male trampolines. The difference between the fat mass of the right and left extremities is $0.043 \pm 0.08$ percent of the body mass of the male elite male trampolines.

\subsection{Competitive Performance of Elite Male Trampolines}

Table 5. Descriptive statistics related to competitive performance

\begin{tabular}{l|l|l|l}
\hline & N & M & SD \\
\hline L5 & 8 & 216.01 & 53.01 \\
\hline L6 & 7 & 230.71 & 61.61 \\
\hline L7 & 8 & 195.25 & 85.08 \\
\hline L8 & 4 & 267.75 & 17.03 \\
\hline Youth & 6 & 21603 & 33.05 \\
\hline Adults & 12 & 226.66 & 61.09 \\
\hline Total & 45 & 221.85 & 59.89 \\
\hline
\end{tabular}

Table 5 shows that the competitive performance of elite male trampolines in different age groups and the competitive performance of the entire participant.

Table 6. Pearson correlation coefficient for determining the relationships between body composition and competitive performance

\begin{tabular}{l|r|r|r|}
\hline Predictive variables & N & $\boldsymbol{p}$ \\
\hline Height & 45 & 0.152 & 0.342 \\
\hline Body mass & 45 & 0.181 & 0.256 \\
\hline Body mass index & 45 & 0.201 & 0.209 \\
\hline Percentage of water in the body of the body & 45 & 0.021 & 0.895 \\
\hline Body protein percentage & 45 & 0.022 & 0.892 \\
\hline Percent mineralization and mineral content of the body & 45 & -0.194 & 0.224 \\
\hline Body fat percentage & 45 & 0.06 & 0.710 \\
\hline Right-fetal fat percentage & 45 & 0.121 & 0.450 \\
\hline Percentage of liposuction of the right hand & 45 & -0.003 & 0.984 \\
\hline The percentage of fat in the right leg & 45 & 0.138 & 0.389 \\
\hline The percentage of left fetal liposome & 45 & 0.095 & 0.553 \\
\hline Percentage of liposomal liposomal penicillin & 45 & 0.007 & 0.964 \\
\hline Percentage of left foot fat & 45 & 0.111 & 0.491 \\
\hline Body fat percentage & 45 & 0.04 & 0.805 \\
\hline Difference in fat mass of the right and left extremities & 45 & -0.008 & 0.963 \\
\hline Percentage of body muscle & 45 & 0.02 & 0.901 \\
\hline Percentage of right extremity muscle & 45 & 0.005 & 0.974 \\
\hline Percentage of right hand muscle & 45 & 0.118 & 0.461 \\
\hline Percentage of right leg muscle & 45 & -0.038 & 0.816 \\
\hline Left limb muscle mass & 45 & 0.011 & 0.948 \\
\hline Left hand muscle mass & 45 & 0.153 & 0.339 \\
\hline Percentage of left foot muscle & 45 & -0.068 & 0.673 \\
\hline The percentage of trunk muscle & 45 & -0.075 & 0.639 \\
\hline Difference in the percentage of right and left muscles of the muscles & 45 & -0.059 & 0.714 \\
\hline
\end{tabular}

Table 6 shows that the relationship between the elite male trampolines with height, body mass, body mass index, body water percentage, protein percentage, soluble mineral content, body fat percentage, right fat percentage, Percentage of fat in right hand, percentage of fat in right leg, left fat percentage, left fat percentage, fat percentage of left foot, trunk fat percentage, difference between left and right fat mass, body mass percentage, percentage of right muscle, right hand muscle , Percentage of right muscle, percentage of left muscle, percentage of left muscle, percentage of left leg muscle, trunk muscle percentage and percentage of left and right leg muscles were statistically significant Therefore, it is concluded that there is no significant relationship between body composition and tamponelli male elite work (in all cases, $\mathrm{p}<0.05)$.

\section{Discussion and Conclusion}

Findings of the study on the composition of the body of elite male trampolines showed that none of the body composition indices was significant with the performance of these athletes. Considering that in many studies, especially in the field of gymnastics (for example, Irratha Amigo et al., 2009; Di Kagno et al., 2009; Nozuhuri, 2011), there are significant correlations between body composition and exercise performance indices Therefore, it seems that the lack of correlation between these variables is related to the characteristics of the samples studied in this study. 
For example, most of the research samples are a combination of athletes with different levels of stress and, consequently, a different body composition strategy facilitates in sampling the ability to discover relationships between body composition indices and athletic performance. But in the present study, the sample was all from the athletes present in the Trampoline team, which, in terms of body composition, were more homogeneous than those of other studies.

Gomez-Landro et al. (2010) found that Spanish elite female gymnasts over 15 years old had $13.37 \%$ fat and mesomorph-indomorph body mass, but under the age of 15 years had body mass of $11.18 \%$ and a balanced physical type. However, in the present study, the percentages of fatty male elite male trampolines for the age group under 15 years old and over 15 years old were $12.13 \pm 4.20$ and $11.02 \pm 4.18$, respectively do not match with findings of Gomez-Landro et al. (2010) about the elite Spanish female trampolines. The discrepancy between these two studies can be attributed largely to the gender and developmental differences between men and women, because with the increase in age, women share a larger proportion of fat mass (Heywood, 2006).

In the studies in gymnastics, body composition indices were important determinants of athletic performance. For example, Emergency (2011) found that elderly male gymnasts had lower fat percentages with higher weight and higher body mass index (high muscle and low fat) with higher competitive performance. Similar findings were found in other studies in the field of gymnastics by Faria and Faria (1989), Grantham (2000), Dashti (2016), Giorpopoulos et al. (2004), Taherkhani (2006), Rodriguez and Bral De La Rosa (2006), Irrata Amigo et al. (2009), and Di Cagno et al. (2008).

However, Gomez-Landro et al. (2010), by comparing their findings with gymnasts reference data, emphasized that trampolines' athletes had a different type of artistic gymnasts, such that trampolines in the body type has a lower ectomorphic component and more indomethers. Accordingly, matching performance predictors in the field of trampolines and gymnastics may be questionable. However, due to the limited information available in the trampoline field, definite comments on the pattern of association between body composition indices and the performance of elite trampolines are difficult, but according to the findings of the present study, we can conclude there is no relation between the body composition and the performance of the elven male trampolines.

\section{References}

Dashti, K., \& Mohammad, H. (2016). Relationship between some anthropometric characteristics and physical fitness factors with the performance of gymnasts in the superior male boys. Master's thesis, University of Guilan, Faculty of Physical Education and Sport Sciences.

Di Cagno, A., Baldari, C., Battaglia, C., Guidetti, L. I., \& Piazza, M. (2008). Anthropometric characteristics evolution in elite rhythmic gymnasts. Italian Journal of Anatomy and Embryology, 113(1), 29-35.

Douda, H. T., Toubekis, A. G., Avloniti A. A., \& Tokmakidi, S. P. (2008). Physiological and anthropometric determinants of rhythmic gymnastics performance. International Journal of Sport Physiology and Performance, 3, 41-45. https://doi.org/10.1123/ijspp.3.1.41

Dzhafarov, M. A., \& Vasil'chuk, A. L. (1987). Anthropometric characteristics of highly qualified female gymnasts. Arkhiv Anatomii Gistologii I Embriologii, 93(8), 33-37.

Faria, I. E., \& Faria, E. W. (1989). Relationship of the anthropometric and physical characteristics of male junior gymnasts to performance. J Sports Med Phys Fitness, 29(4), 369-378.

Georgopoulos, N. A., Theodoropoulou, A., Leglise, M., Vagenakis, A. G., \& Markou, K. B. (2004). Growth and skeletal maturation in male and female artistic gymnasts. The Journal of Clinical Endocrinology \& Metabolism, 89(9), 4377-4382. https://doi.org/10.1210/jc.2003-031864

Gómez-Landero, L. A., Vernetta, M., \& López-Bedoya, J. (2010). Somatotype and body composition in elite Spanish female trampolinist. International Journal of Sport Science, 19(6), 141-153.

Grandjean, B. D., Taylor, P. A., \& Weiner, J. (2002). Confidence, concentration, and competitive performance of elite athletes: a natural experiment in Olympic gymnastics. Journal of Sport \& Exercise Psychology, 24, 320-327. https://doi.org/10.1123/jsep.24.3.320

Grantham, N. J. (2000). Body composition and physiological characteristics of male and female national and international high performance gymnasts. Journal of Sports Sciences, 18(1), 24-35.

Irurtia, A. A., Busquets, F. A., Marina, E. M., Galilea, B. P. A., \& Carrasco, M. M. (2009). Height, weight, somatotype and body composition in elite Spanish gymnasts from childhood to adulthood. Apunts Med Esport, 161, 18-28.

Lindner, K. J., Caine, D. J., \& Johns, D. P. (1991). Withdrawal predictors among physical and performance characteristics of female competitive gymnasts. J. Sports Sci., 9(3), 259-272. 
https://doi.org/10.1080/02640419108729888

Macmillan Reference USA (2007). Prescription Medications and Athletic Performance. World of Sports Science, Retrieved February 03, 2012 from HighBeam Research: http://www.highbeam.com/doc/1G2-3451100415.html

Nozuhuri, H. (2016). The prediction of elite male gymnasts based on self-efficacy, psychological skills and some anthropometric features. Master's Thesis, Shiraz University.

Rodriguez, B. E., \& Berral de la Rosa, F. J. (2006). Morfhological assesment in elite argentineans male gymnasts. Rev Bras Cineantropom Desempenho Hum, 8(4), 16-24.

Sherman, R. T., Thompson, R. A., \& Rose, J. (1996). Body mass index and athletic performance in elite female gymnasts. Journal of Sport Behavior, 19, 338-346.

Taher, K. A. (2011). The prediction of elite male gymnasts based on self-efficacy, psychological skills and some anthropometric features. Master's Thesis, Shiraz University.

Taher, K. A. (2011). The prediction of elite male gymnasts based on self-efficacy, psychological skills and some anthropometric features. Master's Thesis, Shiraz University.

Taher, K. H. (2006). Description of the anthropometric features and mental skills of elite gymnasts in Iran: Applied to talent identification. Master's Thesis, Islamic Azad University, Tehran Branch.

Vandorpe, B., Vandendriessche, J., Vaeyens, R., Pion, J., Lefevre, J., Philippaerts, R., \& Lenoir, M. (2011). Factors Discriminating Gymnasts by Competitive Level. Int. J. Sports Med., 32(8), 591-597. https://doi.org/10.1055/s-0031-1275300

Zuniga, J., Housh, T. J., \& Camic, C. (2011). Yearly changes in the anthropometric dimensions of female high school gymnasts. Journal of Strength \& Conditioning Research, 25(1), 124-128. https://doi.org/10.1519/JSC.0b013e3181bb0d92

\section{Copyrights}

Copyright for this article is retained by the author(s), with first publication rights granted to the journal.

This is an open-access article distributed under the terms and conditions of the Creative Commons Attribution license which permits unrestricted use, distribution, and reproduction in any medium, provided the original work is properly cited. 